\title{
Stimulation of $\alpha_{2}$-Adrenoceptors Suppresses Excitatory Synaptic Transmission in the Medial Prefrontal Cortex of Rat
}

\author{
Xiao-Hua Ji', Jin-Zhao ji', ${ }^{1,3}$ Hui Zhang' and Bao-Ming Li*, 1,2 \\ IInstitute of Neurobiology, Institutes of Brain Science, Fudan University, Shanghai, China; ${ }^{2}$ State Key Laboratory of Medical Neurobiology, Institutes \\ of Brain Science, Fudan University, Shanghai, China
}

\begin{abstract}
Stimulation of $\alpha_{2^{-}}$, especially $\alpha_{2 A}$-adrenoceptor (AR), in the prefrontal cortex (PFC) produces a beneficial effect on cognitive functions such as working memory. $\alpha_{2}$-Adrenergic agonists like clonidine and guanfacine have been used experimentally and clinically for treatment of psychiatric disorders such as attention-deficit/hyperactivity disorder (ADHD) and schizophrenia. However, the neurophysiological actions of $\alpha_{2}$-ARs in the PFC are poorly understood. In the present study, we recorded field excitatory post-synaptic potential (fEPSP) and evoked excitatory post-synaptic current (eEPSC) in the medial prefrontal cortex (mPFC) of rats, using in vivo field-potential recording and in vitro whole-cell patch-clamp recording techniques, and examined the effects of the $\alpha_{2}$-AR agonist clonidine and the selective $\alpha_{2 A^{-}}$ AR agonist guanfacine on fEPSP and eEPSC. Systemic or intra-mPFC application of clonidine or guanfacine significantly reduced fEPSP in the mPFC, either in anesthetized or freely moving rats. Consistently, bath-application of guanfacine suppressed eEPSC in layer V/VI pyramidal neurons, and this effect was blocked by the $\alpha_{2}$-AR antagonist yohimbine or the $G_{i}$ inhibitor NF023. Moreover, treatment with guanfacine had no effect on paired-pulse facilitation (PPF) of fEPSP and eEPSC. The present study provides the first electrophysiological evidence that stimulation of $\alpha_{2 A}$-AR inhibits excitatory synaptic transmission in the mPFC through a post-synaptic mechanism. Neuropsychopharmacology (2008) 33, 2263-227I; doi:I0.1038/sj.npp. I 301603; published online 24 October 2007
\end{abstract}

Keywords: $\alpha_{2}$-adrenoceptor; fEPSP; EPSC; medial prefrontal cortex; rat

\section{INTRODUCTION}

The prefrontal cortex (PFC) is essential for cognitive functions such as working memory (Baddeley, 2003; Bodner et al, 2005; Funahashi et al, 1989, 1993; Fuster, 2003; Goldman-Rakic, 1995; Miller and Cohen, 2001), attention regulation (Dias et al, 1996; Luria, 1966) and response inhibition (Aron et al, 2004; Luria, 1966). Animals or humans with lesions to the PFC exhibit disorganized behaviors like poor working memory, distractibility, impulsivity and hyperactivity (Fuster, 1997; Luria, 1966).

It is well documented that $\alpha_{2^{-}}$, especially $\alpha_{2 \mathrm{~A}}$-adrenoceptors (ARs) in the PFC are involved in regulating working memory function (Arnsten et al, 1988; Arnsten and Goldman-Rakic, 1985; Arnsten and Li, 2005; Franowicz and Arnsten, 1998; Franowicz et al, 2002; Li and Mei, 1994; Mao et al, 1999). $\alpha_{2}$-AR agonists such as clonidine and guanfacine administered systemically or locally into the PFC improve working memory performance in rats and monkeys (Arnsten et al, 1988; Arnsten and Goldman-Rakic,

\footnotetext{
*Correspondence: Dr B-M Li, Laboratory of Higher Brain Functions, Institute of Neurobiology, Fudan University, 138 Yi Xue Yuan Road, Shanghai 200032, China, Tel: 2 I 6422 1979, Fax: 2 I 5423 7647, E-mail: bmli@fudan.edu.cn

${ }^{3}$ These authors contributed equally to this work.

Received 8 March 2007; revised 25 July 2007; accepted 20 September 2007
}

1985; Franowicz and Arnsten, 1998; Mao et al, 1999; Tanila et al, 1996). It has been shown that the beneficial effect of clonidine or guanfacine on working memory performance is mediated by $\alpha_{2 \mathrm{~A}}$-ARs (Arnsten et al, 1988; Arnsten and Li, 2005; Franowicz et al, 2002). In addition to working memory performance, $\alpha_{2 \mathrm{~A}}$-AR stimulation in the PFC also enhances visuomotor association learning in monkeys (Wang et al, 2004a, b).

It has been reported that clonidine and guanfacine are effective for treatment of human psychiatric disorders that involve PFC dysfunctions, such as attention-deficit/hyperactivity disorder (ADHD) (Arnsten et al, 1996; Arnsten and Li, 2005; Chappell et al, 1995; Hunt et al, 1995; Scahill et al, 2001; Taylor and Russo, 2001), schizophrenia (Friedman et al, 2001, 2004) and post-traumatic stress disorder (Horrigan, 1996; Porter and Bell, 1999). Atomoxetine is a reuptake inhibitor of norepinephrine (NE) and has also been used for treatment of ADHD (Gilbert et al, 2007; Perwien et al, 2006). Although both involving a noradrenergic mechanism, atomoxetine increases $\mathrm{NE}$ concentration in synaptic cleft, whereas clonidine and guanfacine directly stimulate post-synaptic $\alpha_{2 \mathrm{~A}^{-}}$receptor.

The effects of $\alpha_{2}$-AR stimulation or blockade on working memory have been investigated at both behavioral and cellular levels. For example, previous studies show that stimulation of $\alpha_{2}$-ARs enhances PFC neuronal activity that is related to working memory (Li et al, 1999; Wang et al, 
2007), while blockade of $\alpha_{2}$-ARs inhibits the working memory-related PFC neuronal activity (Li et al, 1999; Sawaguchi and Yamane, 1999; Wang et al, 2007). However, it is poorly understood how $\alpha_{2}$-ARs regulate synaptic transmission in the PFC. In the present study, we investigated the effects of clonidine and guanfacine on excitatory synaptic transmission in the medial PFC of rats, using in vivo field-potential recording and in vitro wholecell patch-clamp recording. Paired-pulse facilitation (PPF) was recorded and used as a measure to analyze whether a pre- or post-synaptic mechanism is involved in $\alpha_{2}$-AR regulation. We attempted to know how $\alpha_{2 \mathrm{~A}}$-AR stimulation, either by systemic or local administration of clonidine and guanfacine, regulates PFC excitatory synaptic transmission.

\section{MATERIALS AND METHODS}

\section{Drugs}

Clonidine hydrochloride, yohimbine hydrochloride, bicuculline methiodide (BMI), 6-cyano-7-nitroquinoxaline2,3-dione (CNQX), DL-2-amino-5-phosphonovaleric acid (AP-5), $\mathrm{K}^{+}$gluconate, ATP.Mg, GTP.Na ${ }^{+3}$, and HEPES were purchased from Sigma Chemical Company Ltd. (St Louis, MO, USA). NF023 was purchased from Tocris Cookson Ltd. (Ellisville, Missouri, USA) and guanfacine hydrochloride from Wyeth-Ayerst Company Ltd. (Princeton, NJ, USA). Other reagents in AR grade were purchased from the Shanghai Chemical Plant (Shanghai, China). Drugs were dissolved in ultra-pure water produced by an untrapure system (Millipore Q-Gard 1, USA) or sterile saline.

\section{Animals}

Spraque-Dawley (SD) rats (200-250g) were used for in vivo field-potential recording and SD rats of 14-24 days for in vitro whole-cell patch-clamp recording. The animals were purchased from the Laboratory Animal Center, Fudan University Shanghai Medical School. All the experimental protocols used in the present study were in compliance with the NIH Guide for the Care and Use of Laboratory Animals (1996). This study was approved and monitored by the Ethical Committee of Animal Experiments, Fudan University Institute of Neurobiology. All efforts were made to minimize the number of animals used and their suffering.

\section{Implantation of Electrode}

Rats were anesthetized with urethane $(1250 \mathrm{mg} / \mathrm{kg}$, i.p.; for field-potential recordings under anesthesia) or pentobarbital sodium $(40 \mathrm{mg} / \mathrm{kg}$, i.p; for implantation of stimulating and recording electrodes in the medial prefrontal cortex $(\mathrm{mPFC}))$. The animals were fixed in a stereotaxic apparatus (Narishige SN-2, Japan). A stainless-steel guide cannula, with a teflon-coated stainless steel wire glued to it, was inserted to the mPFC (AP, $3.2 \mathrm{~mm}$; ML, $0.6 \mathrm{~mm}$ ). The guide cannula was used for drug infusion and the stainless-steel wire for field-potential recording. The tip of the stainlesssteel wire was $1.0 \mathrm{~mm}$ beyond that of the guide cannula.

A concentric electrode was used as a stimulating electrode, which was inserted to the boundary area of the gray and white matters in the mPFC (AP, $2.7 \mathrm{~mm}$; ML, $2.8 \mathrm{~mm}$ ). A test pulse
( $50 \mu$ s in duration, $300-350 \mu \mathrm{A}$ in intensity) was delivered, once every $30 \mathrm{~s}$, through the stimulating electrode. The tip positions of the stimulating and recording electrodes were adjusted finely and slowly in order to obtain an optimal field excitatory post-synaptic potential (fEPSP).

\section{Recordings of fEPSP in Anesthetized Rats}

Recording of fEPSP under anesthesia began soon after the surgery had been completed. A current intensity that elicited a fEPSP with $\sim 65 \%$ of maximal response was used as a stimulating current. fEPSP was evoked, once every $1 \mathrm{~min}$, by delivering a single current pulse $(50 \mu$ in duration). After a baseline recording of fEPSP for $30 \mathrm{~min}$, clonidine, guanfacine or saline was given systemically or infused into the mPFC through an injection needle. The injection needle was inserted into the guide cannula, with its tip $0.8 \mathrm{~mm}$ beyond that of the guide cannula. Infusion was $1 \mu \mathrm{l}$ in volume and was completed with 3-5 min. The injection needle was left in place throughout a recording experiment. fEPSP was recorded for $120 \mathrm{~min}$ after drug infusion.

PPF of fEPSP was also recorded in the absence and presence of clonidine or guanfacine. A pair of current pulses ( $50 \mu \mathrm{s}$ in pulse duration and $50 \mathrm{~ms}$ in inter-pulse interval) was delivered, once every $10 \mathrm{~min}$. PPF was calculated as the ratio of the slope of second pulse-induced fEPSP to that of the first pulse-induced fEPSP.

\section{Recordings of fEPSP in Freely Moving Rats}

For recordings of fEPSP in freely moving rats, the stimulating and recording electrodes were implanted into the $\mathrm{mPFC}$ and fixed to the skull with dental cement. The animals were allowed 7 days to recover. A current intensity evoking a fEPSP with $\sim 65 \%$ of maximal response was used as a stimulating current. fEPSP was induced, once every $1 \mathrm{~min}$, by delivering a single current pulse $(50 \mu \mathrm{s}$ in duration). After a 30-min baseline recording, clonidine, guanfacine or saline was administered, either systemically or locally. For local infusion, the animals were handled gently and an injection needle was inserted in the guide cannula. The tip of the infusion needle was placed $0.8 \mathrm{~mm}$ beyond that of the guide cannula. Infusion was $1 \mu \mathrm{l}$ in volume and was completed with 3-5 min. The infusion needle was left in place throughout a recording experiment. fEPSP was recorded for $120 \mathrm{~min}$ after drug infusion.

\section{Whole-Cell Recordings of eEPSC in Slices}

Rats were anesthetized with sodium pentobarbital ( $40 \mathrm{mg} / \mathrm{kg}$, i.p.) before decapitation. The brains were quickly removed, submerged in ice-cold artificial cerebrospinal fluid (ACSF) containing (in $\mathrm{mM}$ ): $119 \mathrm{NaCl}, 2.5 \mathrm{KCl}$, $1 \mathrm{CaCl}_{2}, 3 \mathrm{MgSO}_{4}, 1 \mathrm{NaH}_{2} \mathrm{PO}_{4}, 26.2 \mathrm{NaHCO}_{3}, 11$ glucose, and saturated with $95 \% \mathrm{O}_{2}-5 \% \mathrm{CO}_{2}$. Coronal slices $(400 \mu \mathrm{m}$ in thickness), which contained the MPFC, were cut on a Vibroslice (MA752, Campden Instruments, USA). The anatomic locations of these slices were assessed with reference to Paxinos and Watson (Paxinos and Watson, 1986). Brain slices were transferred and incubated in ACSF for at least $1 \mathrm{~h}$ at room temperature, while constantly oxygenated with $95 \% \mathrm{O}_{2}-5 \% \mathrm{CO}_{2}$. After incubation, a single 
slice was transferred to a submerged recording chamber. The perfusion ACSF, which was continuously oxygenated, was delivered with a pump (Peri-Star 291, World Precision Instruments, USA) at a rate of $2-3 \mathrm{ml}$ per min. In the perfusion ACSF, the concentration of $\mathrm{CaCl}_{2}$ was increased to $2.5 \mathrm{mM}$ and $\mathrm{MgCl}_{2}$ decreased to $1.5 \mathrm{mM}$. All experiments were performed at room temperature.

A slice was viewed with an upright microscope (Axioskopz Fsmot, Zeiss, Germany) equipped with infrared-differential interference contrast (IR-DIC) optics. The image was detected with an IR-sensitive CCD (C2400-79H, Hamamatsu, Japan) and displayed on a black-white TV monitor. Wholecell patch-clamp recordings were made from layer V/VI pyramidal cells in the mPFC. Patch pipettes (3-7 M 2 ) were fabricated from borosilicate tubing $(1.5 \mathrm{~mm}$ OD, $0.86 \mathrm{~mm} \mathrm{ID}$, Sutter Instruments, USA) on a horizontal microelectrode puller (P-97, Sutter Instruments, USA). The internal pipette solution contained (in $\mathrm{mM}$ ): $150 \mathrm{~K}^{+}$gluconate, 0.4 EGTA, 8 $\mathrm{NaCl}, 2$ ATP.Mg, 0.1 GTP. $\mathrm{Na}^{+3}$, and 10 HEPES, with a $\mathrm{pH}$ adjusted to 7.2-7.4 and an osmolarity to $290-320 \mathrm{mOsm}$. The spiking pattern with frequency adaptation in response to a depolarization current was used as a measure for electrophysiological identification of pyramidal neurons. For recordings of evoked excitatory post-synaptic current (eEPSC), a bipolar stimulation electrode was positioned $150-200 \mu \mathrm{m}$ subjacent to a recorded neuron. A current pulse with $50-120 \mu \mathrm{A}$ in intensity and $100 \mu$ s in duration was used as a stimulating current. The current pulse was delivered at $0.033 \mathrm{~Hz}$. eEPSC was recorded in the presence of BMI $(20 \mu \mathrm{M})$ in the perfusion ACSF, which blocked GABAergic transmission in a recorded neuron. Guanfacine and/or yohimbine were bath administered. PPF of eEPSC was also recorded in the absence and presence of guanfacine. To do so, a pair of current pulses with an inter-pulse interval of $50 \mathrm{~ms}$ was delivered, once every $30 \mathrm{~s}$.

Signals were recorded with an HEKA EPC9 amplifier (Heka, Germany) connected to a Digidata interface. The data were digitized and stored on disks using Pulse software (Heka). The series resistance (Rs) was monitored at regular intervals throughout a recording. Data were discarded if Rs changed by $15 \%$. In some neurons recorded, Lucifer yellow $(0.05 \%)$ was filled into patch pipettes and the morphology of the neurons was post-examined using a confocal laser scanning microscope (SP2, Leica, Germany).

\section{Data Analysis}

All data are expressed as mean \pm SEM in the text and figures. Data were statistically compared using paired $t$-test (for within-group comparison, between different time points) or unpaired $t$-test (for between-group comparison, at same time points). Asterisks in the figures indicate a significance level $(P<0.05)$ and $n$ refers to the number of rats or neurons. A trace of synaptic response shown in the figures represents the average of 10 consecutive recordings.

\section{RESULTS}

For systemic administration, three doses of clonidine (0.1, 1.0 , and $2.5 \mathrm{mg} / \mathrm{kg}$ ) or guanfacine $(0.01,0.1$, and $1.0 \mathrm{mg} / \mathrm{kg}$ ) were used. These dose ranges of clonidine or guanfacine could improve PFC function such as working memory (Arnsten and Goldman-Rakic, 1985; Arnsten et al, 1988; Franowicz and Arnsten, 1998, 1999). For local administration, we infused $2.67 \mu \mathrm{g}$ clonidine (in $1 \mu \mathrm{l}$ saline; $5 \mu \mathrm{M}$ ) or $1.3 \mu \mathrm{g}$ guanfacine (in $1 \mu \mathrm{l}$ saline; $5 \mu \mathrm{M}$ ) into the medial PFC.

\section{Stimulation of $\alpha_{2}$-ARs Reduces fEPSP in the mPFC of Anesthetized Rats}

Figure 1 shows the effects of intramuscularly administered clonidine and guanfacine on fEPSP in the MPFC of anesthetized rats. While the slope of fEPSP was not affected by saline, it was significantly reduced following administration of clonidine or guanfacine. For example, the slope of the fEPSP at $90 \mathrm{~min}$ post-administration of clonidine was $88.6 \pm 8.9 \%$ of baseline at the $0.1 \mathrm{mg} / \mathrm{kg}$ dose, $72.6 \pm 4.1 \%$ at the $1.0 \mathrm{mg} / \mathrm{kg}$ dose, and $58.0 \pm 8.1 \%$ at the $2.5 \mathrm{mg} / \mathrm{kg}$ dose (Figure 1a). Similar phenomena were seen following administration with guanfacine. The slope of the fEPSP at 90 min post-administration of guanfacine was $87.5 \pm 6.6 \%$ of baseline at the $0.01 \mathrm{mg} / \mathrm{kg}$ dose, $79.1 \pm 5.7 \%$ at the $0.1 \mathrm{mg} / \mathrm{kg}$ dose, and $87.6 \pm 10.1 \%$ at the $1.0 \mathrm{mg} / \mathrm{kg}$ dose (Figure $1 \mathrm{~b}$ ).
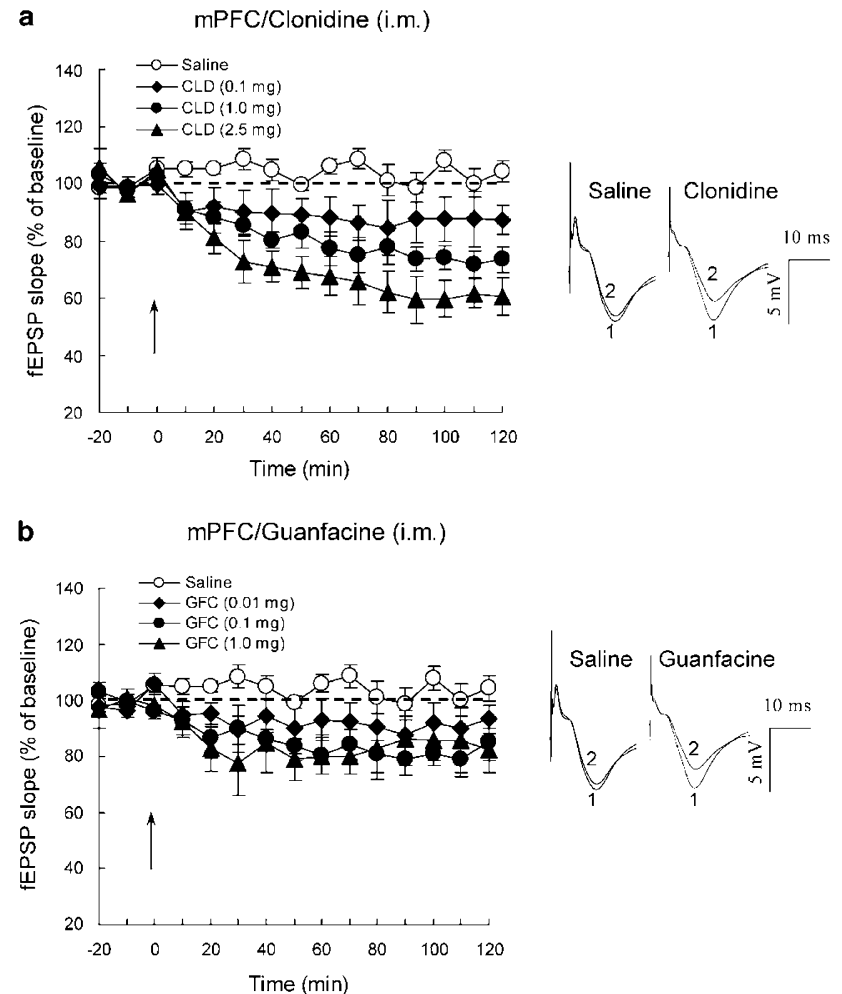

Figure I Systemic administration of the $\alpha_{2}$-AR agonists clonidine and guanfacine suppresses fEPSP in the MPFC of anesthetized rats. (a) Clonidine inhibited fEPSP. The upward arrow indicates the injection time of clonidine (CLD). Saline, $n=6$ rats; CLD $(0.1 \mathrm{mg} / \mathrm{kg}), n=5$ rats; $\operatorname{CLD}(1.0 \mathrm{mg} / \mathrm{kg}), n=6$ rats; CLD $(2.5 \mathrm{mg} / \mathrm{kg}), n=5$ rats. (b) Guanfacine inhibited fEPSP. The upward arrow indicates the injection time of guanfacine (GFC). Saline, $n=6$ rats; GFC $(0.01 \mathrm{mg} / \mathrm{kg}), n=5$ rats; GFC ( $0.1 \mathrm{mg} / \mathrm{kg}), n=5$ rats; GFC ( $1.0 \mathrm{mg} / \mathrm{kg}), n=5$ rats. fEPSP, field excitatory post-synaptic potential; i.m., intramuscular injection; mPFC, medial prefrontal cortex. Shown in the insets are representative fEPSPs recorded $10 \mathrm{~min}$ before (I) and $90 \mathrm{~min}$ after (2) the injection. 
As systemically administered clonidine and guanfacine could act at the whole central nervous system (CNS), we then investigated the effects of locally administered clonidine and guanfacine on fEPSP in the MPFC of anesthetized rats. As shown in Figure 2, intra-mPFC clonidine or guanfacine significantly reduced fEPSP, consistent with the results from systemic administration. The slope of the fEPSP at $90 \mathrm{~min}$ post-infusion of clonidine $(2.67 \mu \mathrm{g} / 1 \mu \mathrm{l})$ was $66.3 \pm 9.0 \%$ of baseline, and it was $61.5 \pm 9.5 \%$ of baseline at $90 \mathrm{~min}$ post-infusion of guanfacine $(1.3 \mu \mathrm{g} / 1 \mu \mathrm{l})$. Thus, stimulation of $\alpha_{2}$-ARs inhibits excitatory synaptic transmission in the mPFC in anesthetized rats.

The clonidine- or guanfacine-inhibition of fEPSP may involve pre- and/or post-synaptic mechanisms. Thus, we tested the effect of intra-mPFC guanfacine on the PPF of fEPSP. PPF of synaptic transmission is thought to be a presynaptically mediated phenomenon (Zucker and Regehr, 2002). A change in PPF by a drug reflects a pre-synaptic site of drug action (Hajos et al, 2001). As shown in Figure 2c, although guanfacine significantly suppressed the fEPSFs induced by the two-paired pulses, the ratio of the second fEPSP to the first fEPSP (ie the PPF of fEPSP) was not changed, suggesting that the guanfacine inhibition of fEPSP did not involve a pre-synaptic mechanism. In other words, the guanfacine inhibition of fEPSP was not due to a decrease in glutamate release from pre-synaptic terminals.

\section{Stimulation of $\alpha_{2}$-ARs Reduces fEPSP in the mPFC of Freely Moving Rats}

The effect of $\alpha_{2}$-AR stimulation on fEPSP of the MPFC was examined in freely moving rats. As shown in Figure 3a, intramuscularly administered clonidine significantly decreased the slope of fEPSP. The slope of fEPSP at $90 \mathrm{~min}$ after injection of clonidine was $81.2 \pm 10.1 \%$ of baseline at the $0.1 \mathrm{mg} / \mathrm{kg}$ dose, $64.2 \pm 6.0 \%$ at the $1.0 \mathrm{mg} / \mathrm{kg}$ dose, and $53.4 \pm 8.3 \%$ at the $2.5 \mathrm{mg} / \mathrm{kg}$ dose. Similar effect was observed following intramuscular administration of guanfacine. As shown in Figure $3 \mathrm{~b}$, guanfacine significantly suppressed fEPSP: the slope of fEPSP at $90 \mathrm{~min}$ after injection of guanfacine was $84.3 \pm 6.2 \%$ of baseline at the $0.01 \mathrm{mg} / \mathrm{kg}$ dose, $79.7 \pm 9.0 \%$ at the $0.1 \mathrm{mg} / \mathrm{kg}$ dose, and $71.7 \pm 4.9 \%$ at the $1.0 \mathrm{mg} / \mathrm{kg}$ dose.

We also investigated the effects of locally administered clonidine and guanfacine on the fEPSP of MPFC in freely moving rats. As shown in Figure 4, intra-mPFC clonidine $(2.67 \mu \mathrm{g} / 1 \mu \mathrm{l})$ or guanfacine $(1.3 \mu \mathrm{g} / 1 \mu \mathrm{l})$ significantly inhibited the fEPSP. The slope of fEPSP at $90 \mathrm{~min}$ postadministration was $63.8 \pm 6.2 \%$ of baseline for clonidine (Figure $4 \mathrm{a}$ ) and $58.7 \pm 10.6 \%$ for guanfacine. Thus, stimulation of $\alpha_{2}$-ARs suppresses excitatory synaptic transmission in the MPFC of freely moving rats.

\section{Stimulation of $\alpha_{2 \mathrm{~A}^{-}} \mathrm{AR}$ Suppresses Evoked-EPSC of $\mathrm{mPFC}$ in Slices}

As shown above, in vivo field-potential recordings indicate that stimulation of $\alpha_{2}$-ARs or $\alpha_{2 \mathrm{~A}}$-AR suppresses excitatory synaptic transmission in the $\mathrm{mPFC}$, most likely via a postsynaptic mechanism. However, because of the technical limitation of the field-potential recording, it was not clear
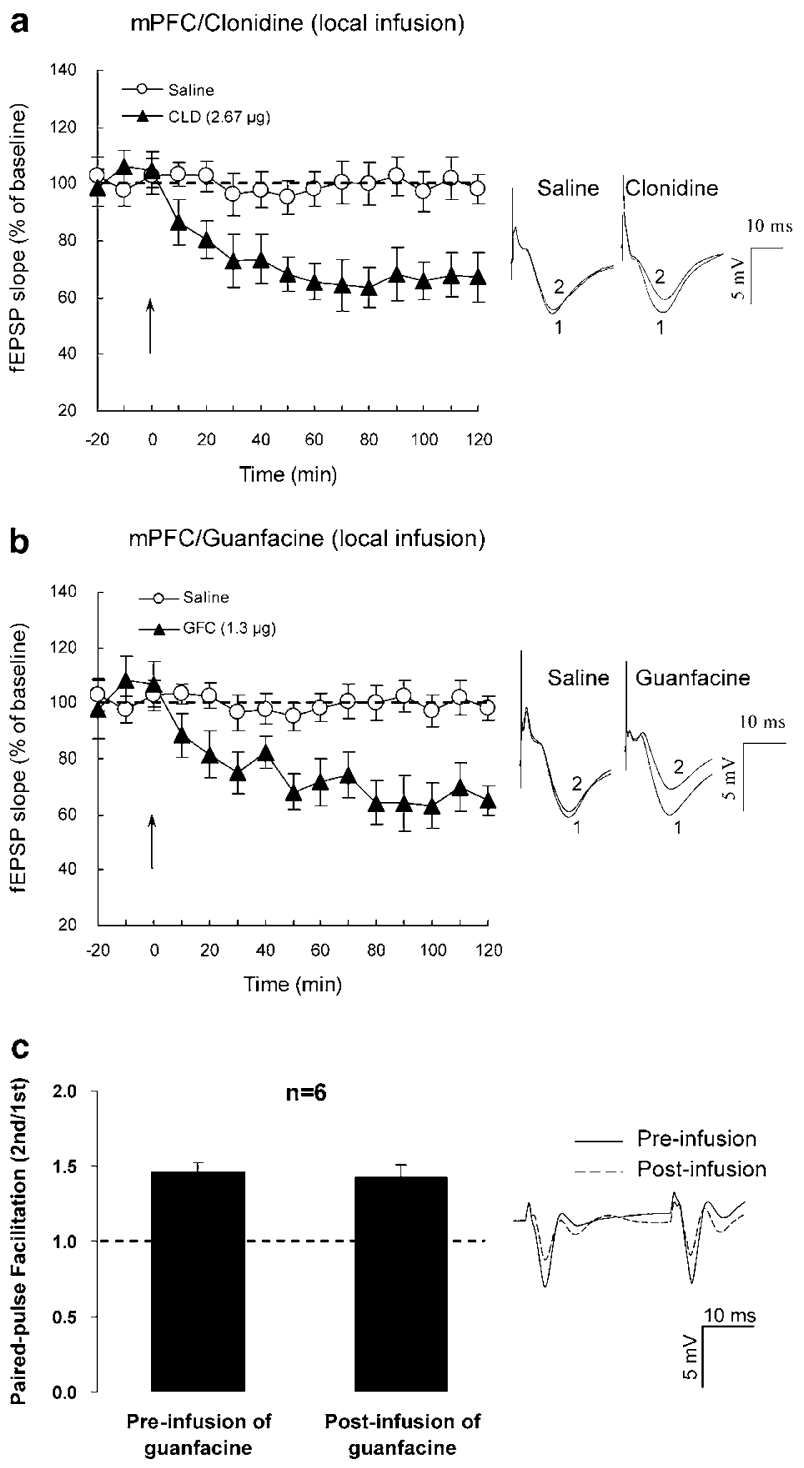

Figure 2 Local administration of the $\alpha_{2}-A R$ agonists clonidine and guanfacine suppresses fEPSP in the mPFC of anesthetized rats. (a) Clonidine with the $2.67 \mu \mathrm{g}$ dose (in $|\mu|$ saline) inhibited fEPSP. The upward arrow indicates the injection time of clonidine (CLD). Saline, $n=5$ rats; CLD $(2.67 \mu \mathrm{g}), n=5$ rats. (b) Guanfacine with the $1.3 \mu \mathrm{g}$ dose (in $|\mu|$ saline) inhibited fEPSP. The upward arrow indicates the injection time of guanfacine (GFC). Saline, $n=5$ rats; GFC (I.3 $3 \mathrm{~g}), n=4$ rats. (c) Guanfacine had no effect on the paired-pulse facilitation of fEPSP. fEPSP, field excitatory post-synaptic potential; mPFC, medial prefrontal cortex. Shown in the left panels are representative fEPSPs recorded $10 \mathrm{~min}$ before (I) and $90 \mathrm{~min}$ after (2) the injection.

whether the inhibitory effect of $\alpha_{2}$-AR stimulation came from direct action of clonidine and guanfacine at $\alpha_{2}$-ARs at pyramidal neurons, or from indirect action of the drugs at $\alpha_{2}$-ARs at inhibitory neurons. Thus, we performed wholecell patch-clamp recordings in vitro to address this question.

Whole-cell recordings were conducted in layer V/VI pyramidal cells in $\mathrm{mPFC}$. The pyramidal neurons were identified using IR-DIC by their pyramidal-shaped cell bodies and the presence of long apical dendrite extending toward superficial layers. The pyramidal neurons examined in the present study had a resting membrane potential 
a

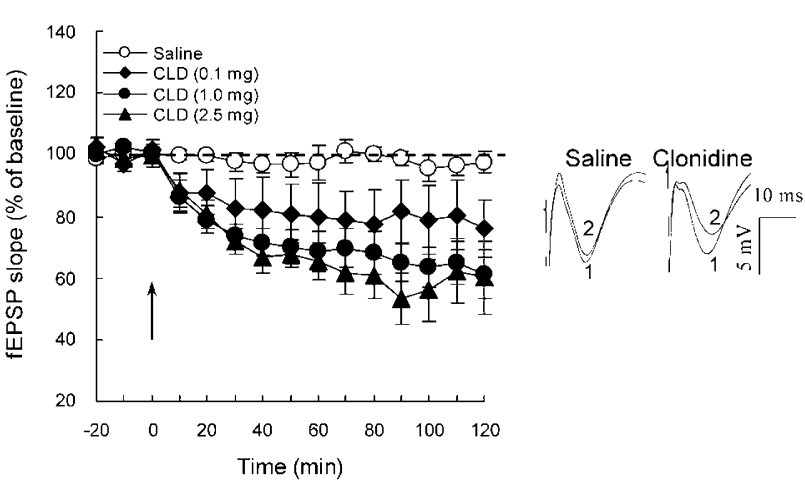

b $\quad \mathrm{mPFC} /$ Guanfacine (i.m.)

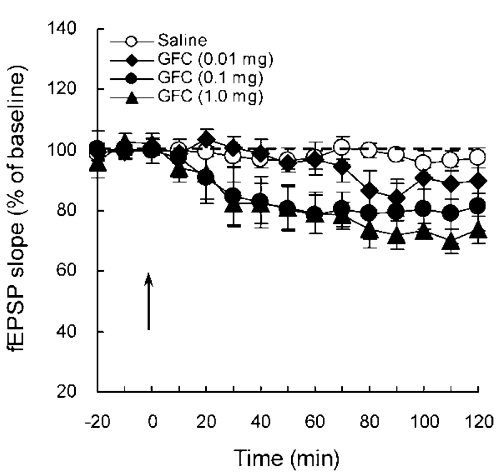

Figure 3 Systemic administration of the $\alpha_{2}$-AR agonists clonidine and guanfacine suppresses fEPSP in the mPFC of freely moving rats. (a) Clonidine inhibited fEPSP. The upward arrow indicates the injection time of clonidine (CLD). Saline, $n=7$ rats; $\operatorname{CLD}(0.1 \mathrm{mg} / \mathrm{kg}), n=6$ rats; CLD $(1.0 \mathrm{mg} / \mathrm{kg}), n=10$ rats; CLD $(2.5 \mathrm{mg} / \mathrm{kg}), n=5$ rats. (b) Guanfacine inhibited fEPSP. The upward arrow indicates the injection time of guanfacine (GFC). Saline, $n=7$ rats; GFC (0.0I mg $/ \mathrm{kg}), n=5$ rats; GFC $(0.1 \mathrm{mg} / \mathrm{kg}), n=6$ rats; GFC ( $1.0 \mathrm{mg} / \mathrm{kg}), n=6$ rats. fEPSP, field excitatory post-synaptic potential; i.m., intramuscular injection; mPFC, medial prefrontal cortex. Shown in the left panels are representative fEPSPs recorded 10 min before (I) and 90 min after (2) the injection.

negative than $-55 \mathrm{mV}$, an action potential amplitude larger than $80 \mathrm{mV}$, with no spontaneous discharge. These neurons exhibited a spike frequency adaptation in response to depolarizing inward current injection ('regular spiking' neurons; Yang et al, 1996). Evoked excitatory post-synaptic current (eEPSC) were recorded in 25 pyramidal cells, under voltage-clamp at a holding potential of $-70 \mathrm{mV}$. The eEPSC could be completely inhibited by co-application of the NMDA-receptor antagonist AP-5 $(50 \mu \mathrm{M})$ and the non-NMDA-receptor antagonist CNQX $(20 \mu \mathrm{M})$, indicating that it was mediated by glutamate receptors.

BMI $(20 \mu \mathrm{M})$, which blocks feed-forward or feedback GABAergic transmission in a recorded pyramidal cell, was bath-applied when eEPSC was recorded. As ionotropic glutamate receptors and/or adrenoceptors (including $\alpha$ ARs) are present not only in pyramidal cells, but also GABAergic interneurons, it is thus necessary to block any possible and indirect influence from GABAergic interneurons when glutamate receptors and adrenoceptors in a patched cell was studied. Hence, in the continuous presence of BMI, the change of eEPSC induced by $\alpha$-AR
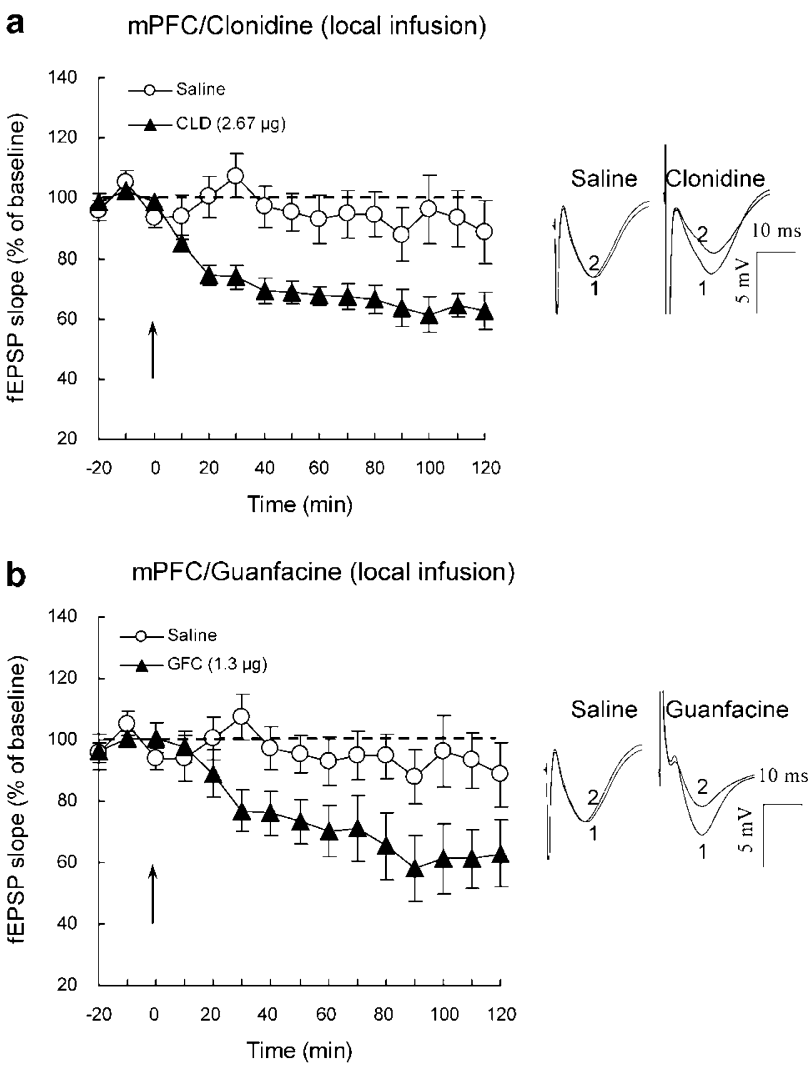

Figure 4 Local administration of the $\alpha_{2}-A R$ agonists clonidine and guanfacine suppresses fEPSP in the mPFC of freely moving rats. (a) Clonidine with the $2.67 \mu \mathrm{g}$ dose (in $|\mu|$ saline) significantly inhibited fEPSP. The upward arrow indicates the injection time of clonidine (CLD). Saline, $n=5$ rats; $\operatorname{CLD}(2.67 \mu \mathrm{g}), n=6$ rats. (b) Guanfacine with the $1.3 \mu \mathrm{g}$ dose (in $|\mu|$ saline) significantly inhibited fEPSP. The upward arrow indicates the injection time of guanfacine (GFC). Saline, $n=5$ rats; GFC $(\mathrm{l} .3 \mu \mathrm{g}), n=6$ rats. fEPSP, field excitatory post-synaptic potential; mPFC, medial prefrontal cortex. Shown in the left panels are representative fEPSPs recorded $10 \mathrm{~min}$ before ( 1 ) and $90 \mathrm{~min}$ after (2) the injection.

stimulation occurs in the recorded cell, but not via GABAergic interneurons.

As shown in Figure 5a, bath application of guanfacine $(20 \mu \mathrm{M})$ significantly inhibited eEPSC: the amplitude of eEPSC was $99.2 \pm 6.1 \mathrm{pA}$ before guanfacine application, and it was $71.7 \pm 4.3 \mathrm{pA}$ during guanfacine application, with a percentage reduction of $27.5 \pm 3.5 \%$. This inhibition was blocked when the non-selective $\alpha_{2}$-AR antagonist yohimbine $(20 \mu \mathrm{M})$ was co-administered.

Figure 5b shows the PPF of eEPSC in the absence (control) and presence of guanfacine. As shown, guanfacine suppressed eEPSC induced by the two-paired pulses, but the ratio of the second eEPSC to the first eEPSC (ie the PPF of eEPSC) was not altered: it was $122.4 \pm 8.1 \%$ in control and $133.1 \pm 12.2 \%$ during guanfacine application, again suggesting that the guanfacine-inhibition of excitatory synaptic transmission was not due to a decrease in glutamate release from pre-synaptic terminals, but involved a post-synaptic mechanism in the recorded cells.

It is known that $\alpha_{2 \mathrm{~A}}-\mathrm{AR}$ is a $\mathrm{G}_{\mathrm{i}}$-coupled metabotropic receptor. We added the $\mathrm{G}_{\mathrm{i}}$ inhibitor NF023 $(10 \mu \mathrm{M})$ into the internal pipette solution in order to block the intracellular 

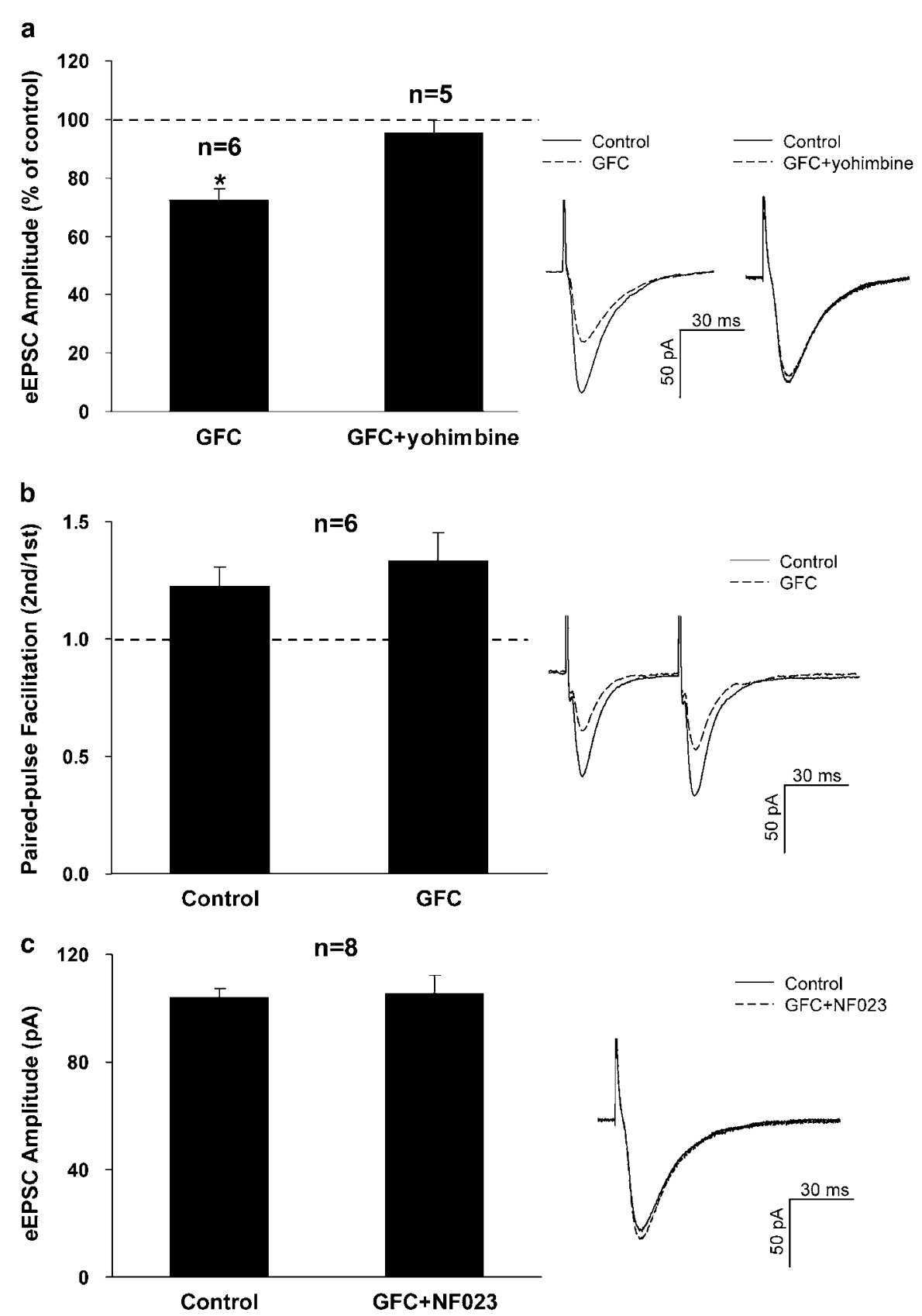

Figure 5 Stimulation of $\alpha_{2 A}$-AR suppresses eEPSC in layer V/VI pyramidal cells in the mPFC. (a) The $\alpha_{2 A}$-AR agonist guanfacine reduced eEPSC, and this inhibitory effect was blocked by the $\alpha_{2}$-AR antagonist yohimbine. $* P<0.05$ vs control. (b) Guanfacine had no effect on paired-pulse facilitation of eEPSC. (c) Guanfacine was without effect on eEPSC in the presence of the $G_{i}$ inhibitor NF023. Holding potential was $-70 \mathrm{mV}$. The concentration of guanfacine and yohimbine was $20 \mu \mathrm{M}$ and that of NF023 (I0 $\mathrm{M}$ ). eEPSC, evoked excitatory post-synaptic current; GFC, guanfacine. Shown in the left panels are representative eEPSCs.

signaling pathway of $\alpha_{2 \mathrm{~A}}$-AR. NF023 could enter into the cytoplasm of a patched cell through the pipette. As shown in Figure $5 c$, guanfacine did not suppress eEPSC in the presence of NF023: the amplitude of eEPSC was $103.0 \pm 3.3 \mathrm{pA}$ in control and $105.4 \pm 6.9 \mathrm{pA}$ in the presence of NF023.

\section{DISCUSSION}

$\mathrm{NE}$, acting on $\alpha_{2}-\mathrm{AR}$, has been reported to produce a beneficial effect on PFC cognitive functions. It has been reported that $\alpha_{2}$-ARs are localized post-synaptic to $\mathrm{NE}$ terminals in the PFC (MacDonald et al, 1997). In the monkey PFC, the post-synaptic $\alpha_{2 \mathrm{~A}}$-ARs are positioned at the dendritic spines of pyramidal neurons (Aoki et al, 1998), where glutamate receptors are concentrated. Thus, it is possible that $\alpha_{2 \mathrm{~A}}$-ARs may exert an influence on glutamate synaptic transmission.

The present study shows that stimulation of $\alpha_{2}$-ARs by clonidine reduced in vivo fEPSP and in vitro eEPSC in layer V/VI pyramidal cells. Stimulation of $\alpha_{2 \mathrm{~A}}$-AR by guanfacine produced a similar effect on fEPSP and eEPSC. Guanfacine had no effect on the PPF of fEPSP and eEPSC, nor when 
intracellular $\mathrm{G}_{\mathrm{i}}$ was blocked. The present results indicate that the $\alpha_{2 \mathrm{~A}}$-AR has an inhibitory regulation on excitatory synaptic transmission in the $\mathrm{mPFC}$, probably through a post-synaptic mechanism. The present study provides electrophysiological evidence that stimulation of $\alpha_{2}$-AR suppresses glutamate synaptic transmission in mPFC.

As systemic administration of clonidine or guanfacine has a beneficial effect on prefrontal cortical cognitive functions, we wanted to know how systemically administered clonidine or guanfacine affects excitatory synaptic transmission in the mPFC. Our results show that intramuscular clonidine and guanfacine both suppressed fEPSP in the MPFC in anesthetized or freely moving rats, indicating that the $\alpha_{2}$-AR agonists could pass the blood-brain barrier and act at $\alpha_{2^{-}}$ ARs in the CNS. As systemically administered clonidine and guanfacine could act at the whole CNS, one may argue that their inhibitory effects may be from the actions of the agonists at $\alpha_{2}$-ARs in other brain areas instead of the mPFC per se. Thus, we observed the effects of direct intra-mPFC infusion of clonidine and guanfacine on fEPSP. We found that locally applied clonidine and guanfacine suppressed fEPSP, either in anesthetized or freely moving rats, as systemically administered clonidine or guanfacine did. The guanfacine inhibition of fEPSP was not mediated by a presynaptic mechanism because the PPF of fEPSP was not altered during the application of guanfacine. Thus, a postsynaptic mechanism may account for the inhibitory regulation of $\alpha_{2 \mathrm{~A}}-\mathrm{AR}$ on excitatory synaptic transmission in the mPFC.

In the present study, the inhibitory effect of systemically administered clonidine on fEPSP was stronger than that of guanfacine (Figures 1 and 3). It is known that $\alpha_{2}$-AR has three subtypes: $\alpha_{2 \mathrm{~A}}, \alpha_{2 \mathrm{~B}}$ and $\alpha_{2 \mathrm{C}}$-ARs. $\alpha_{2 \mathrm{~A}}$-AR is predominately distributed in the PFC, while $\alpha_{2 B^{-}}$and $\alpha_{2 B}$-ARs mainly in other brain regions. While guanfacine is a selective agonist for $\alpha_{2 \mathrm{~A}}-\mathrm{AR}$, clonidine is affinitive for all the three subtypes. It is possible that clonidine also acts at $\alpha_{2 B^{-}}$and $\alpha_{2 C}$-ARs located in other brain regions and produces an indirect influence on PFC excitatory synaptic transmission. It would be also possible that clonidine has a higher permeability than guanfacine to pass the blood-brain barrier.

Field-potential recording technique has its limitation or disadvantage. For instance, we did not know whether the clonidine- and guanfacine-induced suppression of fEPSP came from the direct actions of clonidine and guanfacine at $\alpha_{2}$-ARs at the pyramidal neurons recorded, or from the indirect action of the drugs at $\alpha_{2}$-ARs at inhibitory neurons. To address this problem, we performed whole-cell patchclamp recordings in the slices of $\mathrm{mPFC}$. Our data clearly indicate that guanfacine could act at post-synaptic $\alpha_{2 \mathrm{~A}}$-ARs and produce an inhibitory modulation on glutamate synaptic transmission in the pyramidal cells, because guanfacine inhibition was blocked by the $\alpha_{2}$-AR antagonist yohimbine, guanfacine was without effect on the PPF of eEPSC, and guanfacine inhibition no longer existed when the intracellular $\mathrm{G}_{\mathrm{i}}$ was inhibited.

It is known that $\alpha_{2 \mathrm{~A}}-\mathrm{AR}$ is negatively coupled to adenylyl cyclase by $G_{i}$ protein. Activation of $\alpha_{2 A}$-ARs results in a decrease in the level of intracellular cAMP and thus reduces cAMP-dependent protein kinase (PKA) activity, leading to the activation of protein phosphatase 1 (PP1). PP1 is localized to post-synaptic dendrites (Ouimet et al, 1995) and plays an inhibitory role in synaptic transmission and plasticity through modifying AMPA receptors (Mulkey et al, 1994; Yan et al, 1999), reducing autophosphorylation of CaMKII (Miller and Kennedy, 1986; Miller et al, 1988), and decreasing phosphorylation of GluR1 subunit (Mammen et al, 1997; McGlade-McCulloh et al, 1993). The present study shows that stimulation of $\alpha_{2 \mathrm{~A}}$-ARs inhibits excitatory synaptic transmission in the mPFC, probably involving $\mathrm{G}_{\mathrm{i}^{-}}$ CAMP-PKA-PP1 signaling pathway.

Behavioral electrophysiological studies in monkeys have shown that systemically or iontophoretically applied clonidine enhanced PFC neuronal activity related to working memory (Li et al, 1999; Sawaguchi and Yamane, 1999) or go/no-go performances (Li and Kubota, 1998). Behavioral pharmacological studies in rodents, monkeys, and humans have demonstrated that systemically or locally administered clonidine or guanfacine could improve PFC cognitive performances (Arnsten, 1997; Arnsten et al, 1996; Arnsten and Li, 2005). Brain imaging studies have shown that systemically administered guanfacine enhances regional cerebral blood flow in the PFC in both monkeys and humans (Avery et al, 2000; Swartz et al, 2000). Most recently, Arnsten and colleague have elaborated a model explaining the beneficial effect of $\alpha_{2 \mathrm{~A}}$-AR stimulation on PFC working memory (Wang et al, 2007). In their model, activation of $\alpha_{2 A}$-ARs inhibits the production of cAMP and

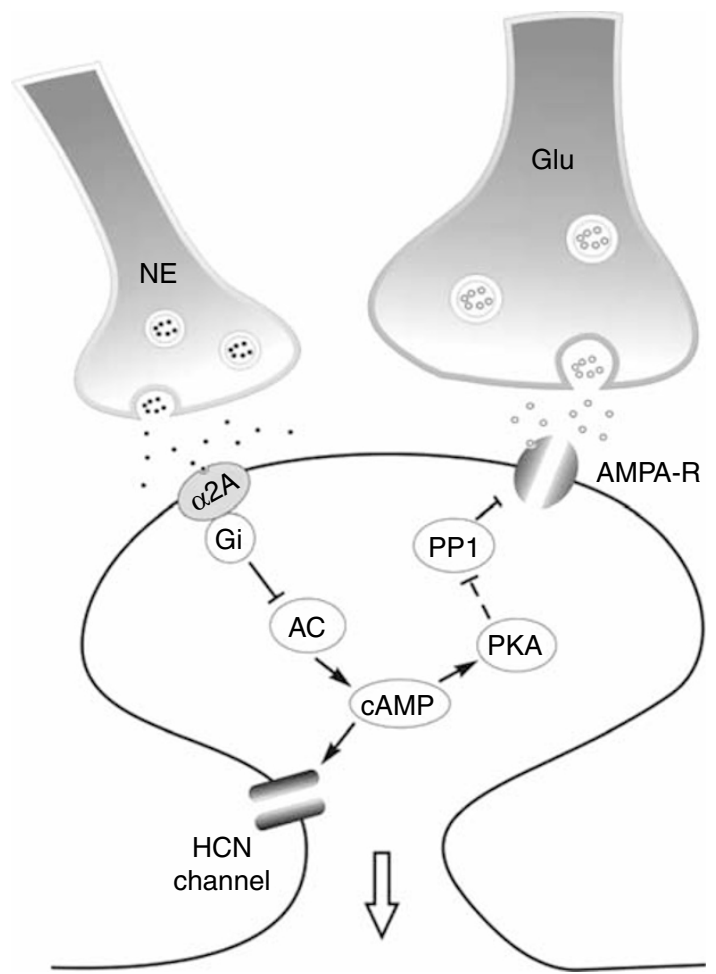

Figure 6 A hypothesized model for bidirectional regulation of PFC excitatory synaptic transmission by $\alpha_{2 A}-A R s$. The $G_{i}-C A M P-H C N$ channel signaling facilitates excitatory cortical inputs on one hand, while the $\mathrm{G}_{\mathrm{i}}$ CAMP-PKA-PPI-AMPA receptor signaling restricts cortical inputs on the other hand. Through this balanced regulation, $\alpha_{2 A}$-ARs tune the synaptic output to an optimal state for working memory. AC, adenylyl cyclase; cAMP, cyclic adenosine monophosphate; Glu, glutamate; HCN, hyperpolarization-activated cyclic nucleotide-gated channel; NE, norepinephrine; PKA, cAMP-dependent protein kinase; PPI, protein phosphatase I. 
shuts down cAMP-dependent HCN channel, therefore enhancing the efficacy of excitatory synaptic inputs in PFC pyramidal cells and strengthening working memory function (Wang et al, 2007).

Thus, there may be a balance mechanism for $\alpha_{2 \mathrm{~A}}$-ARs to tune excitatory inputs in PFC pyramidal cells to an optimal state for working memory (Figure 6): $\alpha_{2 \mathrm{~A}}$-AR stimulation enhances excitatory inputs through $\mathrm{G}_{\mathrm{i}}-\mathrm{cAMP}-\mathrm{HCN}$ pathway on one hand, and restricts them via $\mathrm{G}_{\mathrm{i}}$-cAMP-PKAPP1 pathway on the other hand. The bidirectional regulations determine the strength of synaptic output. The negative regulation by $\alpha_{2 \mathrm{~A}}$-ARs may serve as a protective mechanism for working memory, especially when $\alpha_{2 \mathrm{~A}}$-ARs are overstimulated by high levels of $\mathrm{NE}$ released under stress $\left(\alpha_{2 \mathrm{~A}}\right.$-ARs have a high affinity for NE). Indeed, stimulation of $\alpha_{2 \mathrm{~A}}$-ARs does not always enhance working memory function. For example, iontophoresis of a low dose of guanfacine (at $5 \mathrm{nA}$ ) enhances delay-related firing, while a high dose (at $50 \mathrm{nA}$ ) does not (see Figure $2 \mathrm{~b}$ of Wang et al, 2007).

\section{ACKNOWLEDGEMENTS}

This work was supported by grants to Bao-Ming Li from the Ministry of Science and Technology of China (2006CB500807), the Ministry of Education of China (Program for Changjiang Scholars and Innovative Research Team in University), and the National Natural Science Foundation of China (30225023, 30430240, 30611120530). Technical assistance of Xu Kai-Jing is gratefully acknowledged.

\section{DISCLOSURE/CONFLICT OF INTEREST}

The authors declare that, except for income received from our primary employer, no financial support or compensation has been received from any individual or corporate entity over the past 3 years for research or professional service and there are no personal financial holdings that could be perceived as constituting a potential conflict of interest.

\section{REFERENCES}

Aoki C, Venkatesan C, Go CG, Forman R, Kurose H (1998). Cellular and subcellular sites for noradrenergic action in the monkey dorsolateral prefrontal cortex as revealed by the immunocytochemical localization of noradrenergic receptors and axons. Cereb Cortex 8: 269-277.

Arnsten AF (1997). Catecholamine regulation of the prefrontal cortex. J Psychopharmacol 11: 151-162.

Arnsten AF, Cai JX, Goldman-Rakic PS (1988). The alpha-2 adrenergic agonist guanfacine improves memory in aged monkeys without sedative or hypotensive side effects: evidence for alpha-2 receptor subtypes. J Neurosci 8: 4287-4298.

Arnsten AF, Goldman-Rakic PS (1985). Alpha 2-adrenergic mechanisms in prefrontal cortex associated with cognitive decline in aged nonhuman primates. Science 230: 1273-1276.

Arnsten AF, Li BM (2005). Neurobiology of executive functions: catecholamine influences on prefrontal cortical functions. Biol Psychiatry 57: 1377-1384.

Arnsten AF, Steere JC, Hunt RD (1996). The contribution of alpha 2-noradrenergic mechanisms of prefrontal cortical cognitive function. Potential significance for attention-deficit hyperactivity disorder. Arch Gen Psychiatry 53: 448-455.

Aron AR, Robbins TW, Poldrack RA (2004). Inhibition and the right inferior frontal cortex. Trends Cogn Sci 8: 170-177.

Avery RA, Franowicz JS, Studholme C, van Dyck CH, Arnsten AF (2000). The alpha-2A-adrenoceptor agonist, guanfacine, increases regional cerebral blood flow in dorsolateral prefrontal cortex of monkeys performing a spatial working memory task. Neuropsychopharmacology 23: 240-249.

Baddeley A (2003). Working memory: looking back and looking forward. Nat Rev Neurosci 4: 829-839.

Bodner M, Shafi M, Zhou YD, Fuster JM (2005). Patterned firing of parietal cells in a haptic working memory task. Eur J Neurosci 21: 2538-2546.

Chappell PB, Riddle MA, Scahill L, Lynch KA, Schultz R, Arnsten $\mathrm{AF}$ et al (1995). Guanfacine treatment of comorbid attentiondeficit hyperactivity disorder and Tourette's syndrome: preliminary clinical experience. J Am Acad Child Adolesc Psychiatry 34: $1140-1146$.

Dias R, Robbins TW, Roberts AC (1996). Dissociation in prefrontal cortex of affective and attentional shifts. Nature 380: 69-72.

Franowicz JS, Arnsten AF (1998). The alpha-2a noradrenergic agonist, guanfacine, improves delayed response performance in young adult rhesus monkeys. Psychopharmacology (Berl) 136: 8-14.

Franowicz JS, Arnsten AF (1999). Treatment with the noradrenergic alpha-2 agonist clonidine, but not diazepam, improves spatial working memory in normal young rhesus monkeys. Neuropsychopharmacology 21: 611-621.

Franowicz JS, Kessler LE, Borja CM, Kobilka BK, Limbird LE, Arnsten AF (2002). Mutation of the alpha2A-adrenoceptor impairs working memory performance and annuls cognitive enhancement by guanfacine. J Neurosci 22: 8771-8777.

Friedman JI, Adler DN, Temporini HD, Kemether E, Harvey PD, White $\mathrm{L}$ et al (2001). Guanfacine treatment of cognitive impairment in schizophrenia. Neuropsychopharmacology 25: 402-409.

Friedman JI, Stewart DG, Gorman JM (2004). Potential noradrenergic targets for cognitive enhancement in schizophrenia. CNS Spectr 9: 350-355.

Funahashi S, Bruce CJ, Goldman-Rakic PS (1989). Mnemonic coding of visual space in the monkey's dorsolateral prefrontal cortex. J Neurophysiol 61: 331-349.

Funahashi S, Chafee MV, Goldman-Rakic PS (1993). Prefrontal neuronal activity in rhesus monkeys performing a delayed antisaccade task. Nature 365: 753-756.

Fuster JM (1997). The Prefrontal Cortex: Anatomy, Physiology, and Neuropsychology of the Frontal Lobe, 3rd edn. Maple Press: New York.

Fuster JM (2003). Cortex and Mind: Unifying Cognition. Oxford university press: New York, pp 155-164.

Gilbert DL, Zhang J, Lipps TD, Natarajan N, Brandyberry J, Wang $\mathrm{Z}$ et al (2007). Atomoxetine treatment of ADHD in Tourette Syndrome: reduction in motor cortex inhibition correlates with clinical improvement. Clin Neurophysiol 118: 1835-1841.

Goldman-Rakic PS (1995). Cellular basis of working memory. Neuron 14: 477-485.

Hajos N, Ledent C, Freund TF (2001). Novel cannabinoid-sensitive receptor mediates inhibition of glutamatergic synaptic transmission in the hippocampus. Neuroscience 106: 1-4.

Horrigan JP (1996). Guanfacine for PTSD nightmares. J Am Acad Child Adolesc Psychiatry 35: 975-976.

Hunt RD, Arnsten AF, Asbell MD (1995). An open trial of guanfacine in the treatment of attention-deficit hyperactivity disorder. J Am Acad Child Adolesc Psychiatry 34: 50-54.

Li BM, Kubota K (1998). Alpha-2 adrenergic modulation of prefrontal cortical neuronal activity related to a visual discrimination task with GO and NO-GO performances in monkeys. Neurosci Res 31: 83-95. 
Li BM, Mao ZM, Wang M, Mei ZT (1999). Alpha-2 adrenergic modulation of prefrontal cortical neuronal activity related to spatial working memory in monkeys. Neuropsychopharmacology 21: 601-610.

Li BM, Mei ZT (1994). Delayed-response deficit induced by local injection of the alpha 2-adrenergic antagonist yohimbine into the dorsolateral prefrontal cortex in young adult monkeys. Behav Neural Biol 62: 134-139.

Luria AR (1966). Higher Cortical Function in Man. Basic books: New York, pp 81-292.

MacDonald E, Kobilka BK, Scheinin M (1997). Gene targeting-homing in on alpha 2-adrenoceptor-subtype function. Trends Pharmacol Sci 18: 211-219.

Mammen AL, Kameyama K, Roche KW, Huganir RL (1997). Phosphorylation of the alpha-amino-3-hydroxy-5-methylisoxazole4-propionic acid receptor GluR1 subunit by calcium/ calmodulin-dependent kinase II. J Biol Chem 272: 32528-32533.

Mao ZM, Arnsten AF, Li BM (1999). Local infusion of an alpha-1 adrenergic agonist into the prefrontal cortex impairs spatial working memory performance in monkeys. Biol Psychiatry 46: 1259-1265.

McGlade-McCulloh E, Yamamoto H, Tan SE, Brickey DA, Soderling TR (1993). Phosphorylation and regulation of glutamate receptors by calcium/calmodulin-dependent protein kinase II. Nature 362: 640-642.

Miller EK, Cohen JD (2001). An integrative theory of prefrontal cortex function. Annu Rev Neurosci 24: 167-202.

Miller SG, Kennedy MB (1986). Regulation of brain type II Ca2+/ calmodulin-dependent protein kinase by autophosphorylation: a Ca2+-triggered molecular switch. Cell 44: 861-870.

Miller SG, Patton BL, Kennedy MB (1988). Sequences of autophosphorylation sites in neuronal type II CaM kinase that control Ca2(+)-independent activity. Neuron 1: 593-604.

Mulkey RM, Endo S, Shenolikar S, Malenka RC (1994). Involvement of a calcineurin/inhibitor-1 phosphatase cascade in hippocampal long-term depression. Nature 369: 486-488.

Ouimet CC, da Cruz e Silva EF, Greengard P (1995). The alpha and gamma 1 isoforms of protein phosphatase 1 are highly and specifically concentrated in dendritic spines. Proc Natl Acad Sci USA 92: 3396-3400.

Paxinos G, Watson C (1986). The Rat Brain in Stereotaxic Coordinates, 2nd edn. Academic Press: San Diego.

Perwien AR, Kratochvil CJ, Faries DE, Vaughan BS, Spencer T, Brown RT (2006). Atomoxetine treatment in children and adolescents with attention-deficit hyperactivity disorder: what are the long-term health-related quality-of-life outcomes? J Child Adolesc Psychopharmacol 16: 713-724.

Porter DM, Bell CC (1999). The use of clonidine in post-traumatic stress disorder. J Natl Med Assoc 91: 475-477.

Sawaguchi T, Yamane I (1999). Properties of delay-period neuronal activity in the monkey dorsolateral prefrontal cortex during a spatial delayed matching-to-sample task. J Neurophysiol 82: 2070-2080.

Scahill L, Chappell PB, Kim YS, Schultz RT, Katsovich L, Shepherd E et al (2001). A placebo-controlled study of guanfacine in the treatment of children with tic disorders and attention deficit hyperactivity disorder. Am J Psychiatry 158: 1067-1074.

Swartz BE, Kovalik E, Thomas K, Torgersen D, Mandelkern MA (2000). The effects of an alpha-2 adrenergic agonist, guanfacine, on $\mathrm{rCBF}$ in human cortex in normal controls and subjects with focal epilepsy. Neuropsychopharmacology 23: 263-275.

Tanila H, Rama P, Carlson S (1996). The effects of prefrontal intracortical microinjections of an alpha-2 agonist, alpha-2 antagonist and lidocaine on the delayed alternation performance of aged rats. Brain Res Bull 40: 117-119.

Taylor FB, Russo J (2001). Comparing guanfacine and dextroamphetamine for the treatment of adult attention-deficit/hyperactivity disorder. J Clin Psychopharmacol 21: 223-228.

Wang M, Ji JZ, Li BM (2004a). The alpha(2A)-adrenergic agonist guanfacine improves visuomotor associative learning in monkeys. Neuropsychopharmacology 29: 86-92.

Wang M, Ramos BP, Paspalas CD, Shu Y, Simen A, Duque A et al (2007). Alpha2A-adrenoceptors strengthen working memory networks by inhibiting cAMP-HCN channel signaling in prefrontal cortex. Cell 129: 397-410.

Wang M, Tang ZX, Li BM (2004b). Enhanced visuomotor associative learning following stimulation of alpha 2A-adrenoceptors in the ventral prefrontal cortex in monkeys. Brain Res 1024: 176-182.

Yan Z, Hsieh-Wilson L, Feng J, Tomizawa K, Allen PB, Fienberg AA et al (1999). Protein phosphatase 1 modulation of neostriatal AMPA channels: regulation by DARPP-32 and spinophilin. Nat Neurosci 2: 13-17.

Yang CR, Seamans JK, Gorelova N 1996. Electrophysiological and morphological properties of layers V-VI principal pyramidal cells in rat prefrontal cortex in vitro. J Neurosci 16: 1904-1921.

Zucker RS, Regehr WG (2002). Short-term synaptic plasticity. Annu Rev Physiol 64: 355-405. 